\title{
Research for Unmanned Aerial Vehicle components reliability evaluation model considering the influences of human factors
}

\author{
Yifang Tan ${ }^{1}$, Ding Feng ${ }^{2}$, Hanlin Shen ${ }^{1}$ \\ 1. Aviation engineering institute, Civil Aviation Flight University Of China, China \\ 2. School of electrical engineering, Southwest Jiaotong University, China
}

\begin{abstract}
Human operating error is one of the important factors affecting the reliable operation of unmanned aerial vehicle (UAV) components, however, people always neglect human-operating-error of the existing unmanned aircraft systems and components reliability assessment methods. This article set the problem to the most important position to search, divided the scene of UAV components assignment to the Status debugging monitoring model and Preventive maintenance type. First, analysis of two scenarios UAV components made qualitative analysis of human error using the method of failure mode and effect analysis; and then put forward the two scenarios of human reliability assessment model, used to quantify the probability of human error. In example analysis, it considers the primary factors those affect humans reliability, to calculate and compare the proportion of human error at different situation. Results show that the proposed method can quantify human error probability, and quantitative characterization of human error can affect the reliability of the UAV components.
\end{abstract}

\section{Introduction}

At present, Whether the private company or professional unmanned aerial vehicle (UAV) management department for UAV components using the traditional way to checking and repairing, Maintenance system problems fundamentally have brought certain blindness and speculative to maintenance work, it's easy to cause excess maintenance or inadequate maintenance, which could lead to temporarily eliminated the risk factors or ruled out the fault on the surface, but buried a safety hazard for unmanned aerial vehicle (UAV) components follow-up operation, even the probability of failure is not reduce instead of increase. At the same time, all kinds of type of work staff due to the limited knowledge level, outside pressure interference and psychological quality, etc., may not be able to quickly and accurately finish operation, and create the serious consequences such as equipment damage, expanding failure. Therefore, because the participation of human activity will introduce artificial operation risks inevitably which affects the reliability of the UAV components.

There are existing methods for the reliability analysis of unmanned aerial vehicle (UAV) components, According to Bayes data fusion method, fault tree analysis method, the life distribution of key-module to establish the evaluation model, to reflect the reliability of the unmanned aerial vehicle (UAV) in literature [1]; Literature [2] is on the basis of the proportion distribution method and rate allocation method, through expert method to determine the weight coefficient, and got the UAV system reliability allocation scheme; Power system and the flight control system are important components of the unmanned aerial vehicle (UAV), therefore the system analysis of its failure mode will improve the reliability and reduce the risk of unmanned aerial vehicle (UAV) flight ${ }^{[3-7]}$.It is very necessary to analysis failure mode and characteristic for UAV system failure, by studying the unmanned aircraft maintenance to improve the reliability of the unmanned aerial vehicle (UAV)[8-9]. Although the literature [10] using HFACS model for unmanned aerial vehicle (UAV) accident analysis, mined the key of accident cause, and put forward corresponding safety recommendations to made support for the establishment and perfection of the UAV airworthiness regulations and improve the level of industry safety management. The study of human factors on the unmanned aerial vehicle (UAV) reliability assessment is lack, so it's need to consider human factors of unmanned aerial vehicle (UAV) reliability to research and analysis.

This article according to the execution case and problem of UAV components, research and analysis the human error mechanism and human influence factors those influence the reliability of UAV parts. In these two scenarios, the reliability evaluation model of UAV parts is considered for human error, and the model is improved and improved based on the characteristics and influence of human factors. Set up scenarios and collect data, then, giving results are obtained by example. Verify the feasibility and applicability of the model. Thus, the reliability evaluation of UAV parts is realized. At the same time, improving the reliability of human operation has 
become the key to ensure the safe and reliable operation of UAV parts.

\section{Reliability analysis of considering human factors}

\subsection{FMEA}

FMEA (Failure Mode and Effect Analysis) often used to evaluate potential failure modes and their causes. From the system, it is a way of system safety analysis, based on the system's separable characteristics. It is a design method to improve the reliability of system and equipment according to the system's separable characteristics, the analysis of the components and elements of the system [11]. It analyzes possible failure modes through dividing the system into subsystems with different functions. classifies according to the severity of each potential failure mode. To put forward the possible planning, prevention and improvement methods, eliminate or reduce the possibility of failure.

Therefore, this article uses the method of FMEA to qualitative analysis the failure mode of failures and their causes and consequences of UAV components, it can provide the basis for scene classification of subsequent quantitative calculation of the reliability.

\section{Quantitative analysis of reliability considering human factors}

Human reliability, refers to within the prescribed time limit, if have time requirements), and any required in system operation stage, the probability of successfully completing job or task by humans [12] Research has shown that UAV components failure part failure is caused by human errors in the process of debugging, operation, $10 \% \sim 15 \%$ of the total failure is caused directly by human improper operation [13]. It's enough to cause people's attention to research for unmanned aerial vehicle components reliability evaluation model considering the influences of human factors.

There are many types of UAV components, And all kinds of complicated parts operation condition, The influence of human error factors in different situations are different. Reasonable division of working condition of equipment scene type is the key to accurately quantify human reliability. Through the analysis of the characteristics of artificial operation and the working condition of equipment type,

In this paper, the operation condition of the UAV components scene can be divided into two categories: type: ESM (Equipment State Monitoring), EE\&R (Equipment Examining and Repairing). On the basis of qualitative research of the FMEA forms, put forward the analysis method to quantitative modeling human error probability of the UAV components under different working scene.

Human reliability, refers to within the prescribed time limit, if have time requirements), and any required in system operation stage, the probability of successfully completing job or task by humans ${ }^{[12]}$ 。 Research has shown that UAV components failure part failure is caused by human errors in the process of debugging, operation, $10 \% \sim 15 \%$ of the total failure is caused directly by human improper operation [13]. It's enough to cause people's attention to research for unmanned aerial vehicle components reliability evaluation model considering the influences of human factors.

There are many types of UAV components, And all kinds of complicated parts operation condition, The influence of human error factors in different situations are different. Reasonable division of working condition of equipment scene type is the key to accurately quantify human reliability. Through the analysis of the characteristics of artificial operation and the working condition of equipment type, In this paper, the operation condition of the UAV components scene can be divided into two categories: type: ESM (Equipment State Monitoring), EE\&R (Equipment Examining and Repairing). On the basis of qualitative research of the FMEA forms, put forward the analysis method to quantitative modeling human error probability of the UAV components under different working scene.

\subsection{Human reliability analysis of unmanned aerial vehicle (UAV) components in equipment state monitoring (ESM-HRA)}

UAV components state surveillance scenes, means the task scenarios that need a long time for continuous inspection, monitoring and debugging of UAV components, at this point, the continuous working time is the dominant position, working long hours can make people appear low energy, such as fatigue state. At the beginning of the unmanned aerial vehicle (UAV) components debugging and monitoring work stage, the personnel on duty state is the best, human error probability HEP remain at low levels. But with the increase of personnel continuous operation time, the probability of human error HEP also will increase. In addition, HEP also will be affected by many other outside covariates including the cognitive level, the working environment, work intensity, physiological factors, psychological factors and the training level.

The human error probability calculation adopts the PHM (proportion hazard model) that was put forward firstly by D.R.Cox in the early $1970 \mathrm{~s}^{[14]}$, The model considered a series of factors such as the equipment state parameters, work load and failure as the impact factors of the life ${ }^{[15]}$ 。Widely used in the field of reliability analysis. The failure rate function form:

$$
h(t, Z)=h_{0}(t) \psi(Z)
$$

Among them, $h_{0}(t)$ is hazard function , said human errors change with working time.

The functional form had no special requirements, the application can choose the reliability parameter distribution according to actual systems or components, one of the most common is two parameter Weibull distribution ${ }^{[16]}$. Its function is:

$$
h_{0}(t)=\beta t^{\beta-1} / \alpha^{\beta}
$$

In the formula, $\alpha$ is the characteristic parameters of life; $\beta$ 
is the shape parameter.

$\Psi(\mathrm{Z})$ is the connection function, it is the influence on human errors of 6 other collaborators variables (cognitive level, the working environment, work intensity, physiological factors, psychological factors and training level), each collaborators variable can be quantified for a particular measurement evaluation value. $Z=\left[Z_{1}, Z_{2}, Z_{3}\right.$, $\left.Z_{4}, Z_{5}, Z_{6}\right]$, the influence index of each collaborators variable $Z_{i}(i=1,2,3 \ldots 6)$ can be $\{0,1,2\}$, The larger value indicates that the negative effect on the human operating reliability of the the variable is more obvious, and vice versa. $\gamma$ is every collaborator variable weight coefficient. Its function is:

$$
\psi(Z)=\exp \left(\sum \gamma \times Z\right)
$$

If the installation personnel began to perform a task from zero moment, continue to perform to $t$ moments don't have the probability of human error is the operation reliability of function, its expression is:

$$
R_{h}(t)=\exp \left[-\int_{0}^{t} h(s, Z) d s\right]
$$

The probability of human error HEP is:

$$
H E P=1-R_{h}(t)
$$

\subsection{Human reliability analysis of unmanned aerial vehicle (UAV) components in equipment examining and repairing (EE\&R-HRA)}

UAV components preventive maintenance scenarios is according to certain standard and cycle, to regularly check of regulation of unmanned aerial vehicle (UAV) components, and ensure unmanned aerial vehicle (UAV) normal state. In this scenario, this paper uses the CREAM(Cognitive Reliability and Error Analysis Method ) [16-17]. The main idea of this method is that human error is not random, but caused by the operators cognitive mode and the specific operation scene controlling and need according to certain process to complete. The direct statistics from the scene cannot be accurately and objectively reflect a series of factors change at any time including the external environment of operation, the operation staff psychological quality, human conditions and so on, but CREAM got a more specific, accurate, objective and quantitative human errors probability at the specific task scenario by CPC

(Common performance conditions) impact factor repairing human error.

Table 1 is the relationship between general efficiency conditions of $\mathrm{CPC}$ and the expectation effect of the CREAM, shows the quantification of the influence on people's cognitive errors.

\begin{tabular}{|c|c|c|}
\hline \multirow{3}{*}{$\begin{array}{l}\text { 2. Working } \\
\text { condition }\end{array}$} & Superior $(8-10)$ & 1 \\
\hline & Matching (4-7) & 0 \\
\hline & Mismatching ( 0-3) & -1 \\
\hline \multirow{4}{*}{$\begin{array}{l}\text { 3.Man-machine } \\
\text { interface }\end{array}$} & Support (9-10) & 1 \\
\hline & Adequate ( 6-8) & 0 \\
\hline & Tolerable (3-5) & 0 \\
\hline & Inaptitude ( $0-2)$ & -1 \\
\hline \multirow{3}{*}{$\begin{array}{ll}4 . & \text { Plan } \\
\text { availability } & \end{array}$} & Appropriate ( 8-10) & 1 \\
\hline & Acceptable ( 4-7) & 0 \\
\hline & Impropriety ( 0-3) & -1 \\
\hline \multirow{3}{*}{$\begin{array}{l}\text { 5. Target number } \\
\text { at the same time }\end{array}$} & Within the ability ( $8-10)$ & 1 \\
\hline & Conformity ability (4-7) & 0 \\
\hline & Beyond the ability ( $0-3)$ & -1 \\
\hline \multirow{3}{*}{ 6. Available time } & Adequate ( 8-10) & 1 \\
\hline & Temporary shortage (4-7) & 0 \\
\hline & Lack of continuous ( $0-3)$ & -1 \\
\hline \multirow{2}{*}{ 7. On duty time } & Day (6-10) & 0 \\
\hline & Night ( 0-5) & -1 \\
\hline \multirow{3}{*}{$\begin{array}{l}\text { 8.Training } \\
\text { experience } \\
\text { adequacy }\end{array}$} & Experienced ( 8-10) & 1 \\
\hline & Experience limited ( 4-7) & 0 \\
\hline & Inadequacy ( 0-3) & -1 \\
\hline \multirow{4}{*}{$\begin{array}{l}\text { 9. Quality of } \\
\text { team cooperation }\end{array}$} & Very effective (9-10) & 1 \\
\hline & Effective ( 6-8) & 0 \\
\hline & Invalid ( $3-5)$ & 0 \\
\hline & Poor effect ( $0-2)$ & -1 \\
\hline
\end{tabular}

Table 1. Common performance conditions CPC

\begin{tabular}{|l|c|c|}
\hline $\begin{array}{c}\text { CPC name and } \\
\text { number (i) }\end{array}$ & level & $\begin{array}{c}\text { Expectation } \\
\text { effect (Si) }\end{array}$ \\
\hline \multirow{3}{*}{$\begin{array}{l}\text { 1.Organization } \\
\text { integrity }\end{array}$} & Very effective (9-10) & 1 \\
\cline { 2 - 3 } & Effective (6-8) & 0 \\
\cline { 2 - 3 } & Invalid (3-5) & 0 \\
\cline { 2 - 3 } & Effect poor (0-2) & -1 \\
\hline
\end{tabular}

Model assumption:

(1) The task environment is continuous, and the human error probability of any point on the continuous space can be quantitative calculated by the human error probability prediction model.

(2)It can be described with a logarithmic relationship between the change of task environmental conditions with increasing or reducing of human respond ability ${ }^{[18]}$ 。

Quantification and weight set for HEP influence level with CPC:

CREAM method using level of CPC to describe the task environment, each CPC factor importance should be differentiated different in task environments, so it should determine the corresponding weights of CPC at the specific task environment firstly. It is $W_{i}$ 。

The integer $1,0,1$ represent the three performance expectation effect, said the quantitative influence on people's cognitive errors. That determines the individual scores of CPC, as $S_{i}$. Specific processing: improved corresponding to 1 , reduced corresponding 1 , not significant is corresponding to 0 . As shown in table 1 column 3. Set of two variables: $I=\sum$ improved score values, $R=\sum$ lower total value.

$$
I=\sum_{i=1}^{9} W_{i} \times S_{i}\left(\mathrm{~S}_{i}=1, \mathrm{i}=1,2, \ldots, 9\right)
$$




$$
R=\sum_{i=1}^{9} W_{i} \times S_{i}\left(\mathrm{~S}_{i}=-1, \mathrm{i}=1,2, \ldots, 9\right)
$$

Operators task environment factors can be divided into two categories: improvement and reduction for human factors reliability. The first category: CPC that only cause improvement effect, the corresponding HEP (Human error aim-listed probability) is $H E P_{I}$, the second category: CPC that only cause reduction effect, the corresponding HEP is $H E P_{R}$. In addition to set up a basic environment: all the influence degree of the CPC to the human factors reliability is not significant, that is $S_{i}=0(\mathrm{i}=1,2 \ldots 9)$, at this point the corresponding HEP is $H E P_{0}$, and the total human error probability is $H E P$. The model hypothesis (2) can get the following expression:

$$
\begin{aligned}
\log \left(H E P_{I} / H E P_{0}\right) & =k_{1} I \\
\log \left(H E P_{R} / H E P_{0}\right) & =k_{2} R
\end{aligned}
$$

Thus the relationship of $H E P_{I}, H E P_{R}, H E P_{0}, I, R$ is established:

$$
\begin{aligned}
& H E P_{I}=H E P_{0} \times 10^{k_{1} I} \\
& H E P_{R}=H E P_{0} \times 10^{k_{2} R}
\end{aligned}
$$

Table 2. The Basis of Failure Probability in Different Failure Modes in CREAM

\begin{tabular}{|c|l|c|}
\hline $\begin{array}{c}\text { Cognitive } \\
\text { behavior }\end{array}$ & Failure Modes & Probability \\
\hline \multirow{4}{*}{$\begin{array}{c}\text { Observation } \\
(\mathrm{P} 1)\end{array}$} & $\begin{array}{l}\text { Observation target error } \\
(\mathrm{P} 11)\end{array}$ & 0.0010 \\
\cline { 2 - 3 } & Misidentification (P12) & 0.0700 \\
\cline { 2 - 3 } & $\begin{array}{l}\text { Observation is not done } \\
(\mathrm{P} 13)\end{array}$ & 0.0700 \\
\hline \multirow{2}{*}{$\begin{array}{c}\text { Explanation } \\
(\mathrm{P} 2)\end{array}$} & Diagnosis Failure (P21) & 0.0200 \\
\cline { 2 - 3 } & Decision Failure (P22) & 0.0100 \\
\cline { 2 - 3 } & Delay to explain (P23) & 0.0100 \\
\hline \multirow{2}{*}{ Plan (P3) } & Priority error (P31) & 0.0100 \\
\cline { 2 - 3 } & Improper planning (P32) & 0.0100 \\
\hline \multirow{3}{*}{$\begin{array}{c}\text { Execution } \\
(\mathrm{P} 4)\end{array}$} & Action mode error (P41) & 0.0030 \\
\cline { 2 - 3 } & Action time error (P42) & 0.0030 \\
\cline { 2 - 3 } & Action target error (P43) & 0.0005 \\
\cline { 2 - 3 } & $\begin{array}{l}\text { Action sequence error } \\
(\text { P44) }\end{array}$ & 0.0030 \\
\cline { 2 - 3 } & Action omission (P45) & 0.0300 \\
\hline
\end{tabular}

$H E P_{0}$ value can be calculated by the table 2 , and then determine the values of parameters $k_{1}, k_{2}$, the ultimate human error probability HEP values as follows:

$$
\begin{gathered}
H E P=\left(H E P_{I}-H E P_{0}\right)+\left(H E P_{R}-H E P_{0}\right)+H E P_{0} \\
H E P=H E P_{0} \times\left(10^{-k_{1} I}+10^{k_{2} R}-1\right)
\end{gathered}
$$

Selection of unmanned aerial vehicle (UAV) system6 collaborators under three different operating state variables influence index $\mathrm{Z}_{\mathrm{i}}(\mathrm{i}=1,2,3, \ldots, 6)$ values and through the analytic hierarchy process to get value of 6 collaborators variable weighting coefficient $\gamma$. Shown in the following table

Table 3.6 covariates influence index and weight

\begin{tabular}{|c|c|c|c|c|c|c|}
\hline $\begin{array}{c}\text { Influen } \\
\text { ce } \\
\text { factor }\end{array}$ & $\begin{array}{c}\text { Cog } \\
\text { nitiv } \\
\mathbf{e} \\
\text { level }\end{array}$ & $\begin{array}{c}\text { operati } \\
\text { ng } \\
\text { environ } \\
\text { ment }\end{array}$ & $\begin{array}{c}\text { oper } \\
\text { ating } \\
\text { inten } \\
\text { sity }\end{array}$ & $\begin{array}{c}\text { phys } \\
\text { iolog } \\
\text { ical } \\
\text { fact } \\
\text { ors }\end{array}$ & $\begin{array}{c}\text { Psychol } \\
\text { ogical } \\
\text { factors }\end{array}$ & $\begin{array}{c}\text { Trai } \\
\text { ning } \\
\text { level }\end{array}$ \\
\hline $\mathbf{Z}_{\mathbf{1}}$ & $\mathbf{Z}_{\mathbf{2}}$ & $\mathbf{Z}_{\mathbf{3}}$ & $\mathbf{Z}_{\mathbf{4}}$ & $\mathbf{Z}_{\mathbf{5}}$ & $\mathbf{Z}_{\mathbf{6}}$ \\
\hline Scene1 & 0 & 0 & 1 & 0 & 0 & 0 \\
\hline Scene2 & 1 & 1 & 1 & 1 & 1 & 1 \\
\hline Scene3 & 2 & 2 & 1 & 2 & 2 & 2 \\
\hline Scene4 & 2 & 0 & 0 & 0 & 0 & 0 \\
\hline Scene5 & 0 & 0 & 0 & 0 & 2 & 0 \\
\hline Scene6 & 0 & 0 & 0 & 0 & 0 & 2 \\
\hline weight & 0.26 & 0.07 & 0.14 & 0.05 & 0.09 & 0.39 \\
\hline
\end{tabular}

From the table above, the work intensity of the three scenarios are still in the general level (grade 1), the other five covariate effects on human error probability $H E P$. MATLAB simulation of the final diagram below:

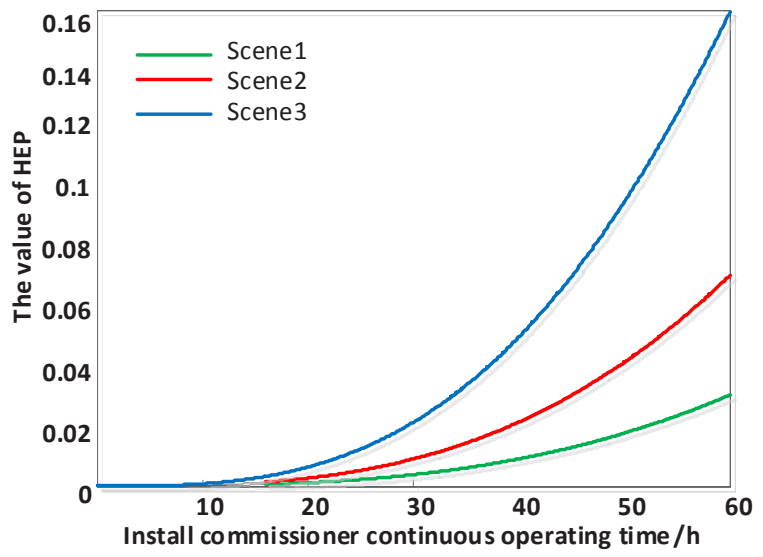

Figure 1. HEP with continuous working time curve

The last three kinds of circumstances in table 3, operating environment, work intensity, physiological factors that 3 collaborators variable values can promote the human operating reliability. In scene 4 , the cognitive level is the most negative effect on the results, in scene 5, the psychological factors is the most negative effect on the results, in scene 6 , the training level is the most negative effect on the results. The MATLAB simulation as shown in figure 2:

\section{Example analysis}

Select the example scenario is that the installation personnel state monitoring and debugging unmanned aerial vehicle (UAV) components of the management.

The Weibull parameters in the model can get through the historical data evaluation ${ }^{[12]}, \quad a=200 、 \beta=3$; 


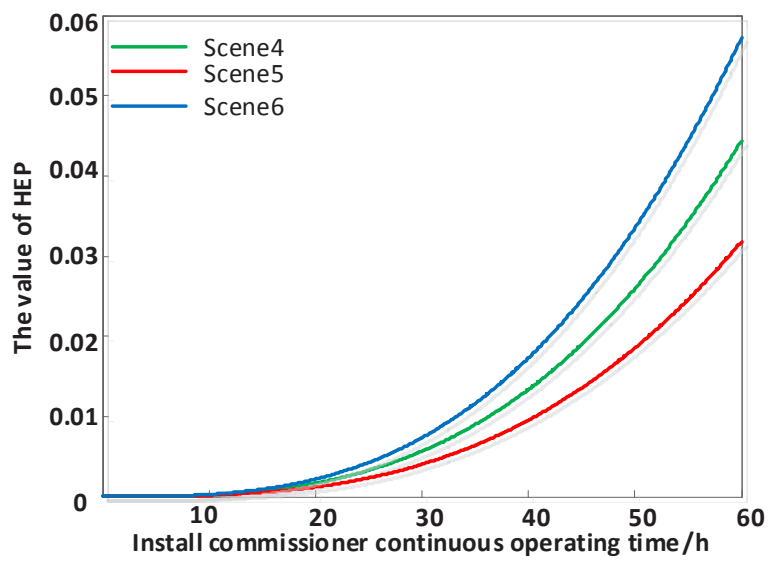

Figure 2. HEP with continuous working time curve

Results analysis:

1) The figure 1 shows that under the same work intensity, five other collaborators variables: cognitive level, working environment, physiological factors, psychological factors and training level have the lower value that the more significant promoting effect on the operating reliability, eventually the human error probability value is smaller, the operating reliability is higher. Thus, management department should make the operator with UAV components installation and debugging work in harmony, reduce such as fatigue, poor health, inattention, low technical level, lack of experience and operation technology is not skilled and so on unstable factors, strengthen the inspection of parts, confirm components state of technology, potential for may affect the safe operation of the UAV components timely report, handle in time.to improve the reliability of the UAV components running.

2) The figure 2 shows that, training level, cognitive level and psychological factors that 3 collaborators variable degree of influence on human error probability HEP from high to low arrangement. the 3 collaborators variable level are relatively easy to improve through artificially training. Therefore, managers should do a good job for staff training, strengthen the training of the personnel cognitive level and psychological quality assessment, to ensure operational reliability.

3) Combined with figure 1 and figure 2, in the first ten hours of continuous operation of personnel installation and debugging, Human errors HEP has maintained at the lower value, personnel operating reliability is higher at this stage. So the management department should perfect the related system, try to avoid same class staff long time continuous operation.

\section{Conclusion}

Human error is an important factor effecting the reliability of UAV components. This paper draws on research in the field of human reliability analysis, qualitative and quantitative analysis of the human error factors influents in the operating process of unmanned aerial vehicle (UAV) components. After considering the characteristics of its operating, involved the artificial operation scene into two classes, put forward the quantitative method of human error probability under different scenarios. The example analysis results show that, this method can consider the influence of personnel operation behavior, quantify the probability of human error and change trends. In the study of UAV system safe operation and accident prevention, according to the results of quantitative analysis, find out greater influence element of the human reliability, and put forward the targeted improvement measures, in order to reduce the occurrence probability of human error, to improve the overall reliability of the UAV system.

\section{References}

1. Wang Dawei, Wang Wei, Zhang Tiechun. Unmanned aerial vehicle (UAV) with a small aircraft engine reliability evaluation [J]. Journal of China civil aviation university, 2012, 30 (01) : 14$17+40$..

2. Zhang Rui, Li Bo. UAV system reliability allocation method [J] Journal of Nanjing university of aeronautics and astronautics, 2009, 9 (S1) : 106-108

3. Feng Jun. Unmanned aerial vehicles based on FTF method of hydraulic and air conditioning system reliability analysis [D]. University of electronic science and technology, 2011.

4. Chen Yuan. Aircraft power system reliability analysis based on fuzzy FMECA method research [D]. University of electronic science and technology, 2011.

5. Shi Weiping, Han Mei. UAV servo mechanism with Angle sensor fault analysis and countermeasures [J]. Journal of quality and reliability, 2011 (2):50-52.

6. Ji Hui, Pan Shengbing, Zhang Xiaojing, etc. Unmanned aerial vehicle (UAV) fault tolerant flight control systems [J]. Journal of research and application of computer measurement and control, 2013, 21 (9).

7. JiHui, Pan sheng-bing, Zhang Xiao-lin. Flight control system fault diagnosis and reconstruction technology research [J]. Computer measurement and control, 2015, 23 (4): 1073-1074.

8. PuHai, Chen Zi-li. Reliability centered maintenance analysis technology and its use in unmanned aerial vehicle (UAV) [C]. Application of high and new technology to improve maintenance support capability conference. 2005.

9. Liu Jian-shan. Unmanned aerial vehicle (UAV) cooperative maintenance technology research [C]. Aviation equipment maintenance technology and application international symposium. 2015.

10. Lu Xiaojian, He Qiang. Human factors analysis of the UAV accident based on HFACS [J]. Science and technology wind, 2017 (17) : 245.

11. Yue Zhang, Chao Shi, Laihua Fang. Study on comprehensive analytical method and its application based on FMEA and HAZOP[J]. Journal of Safety Science and Technology , 2011,7(7):146-150.

12. BS Dillon (Canada), Mou Zhizhong, Xie Xiuling, Wu Fubang. The reliability of [M]. Shanghai: Shanghai science and Technology Press, 1990.

13. Hu Guo, Wenhua Chen, Weie Zhang, etal. Human Reliability Analysis of Operators under the Fluctuating Pressure [J]. Transactions of The Chinese Society of Agricultural Machinery .2002, 33(6): 107-109.

14. Cox D R. Regression models and life: tables, breakthroughs in statistics[M]. New York: Springer, 1992: 527-541.

15. Jiang S T, Landers T L, Rhoad T R. Assessment of Repairablesystem Reliability Using Proportional Intensity Model: a Review [J]. IEEE Transactions on Reliability,2006,55 (2) : 328-336.

16. Hollnagel E. Cognitive reliability and error analysis $\operatorname{method}[\mathrm{M}]$.

Amsterdam: Elsevier, 1998: 151-189.

17. Fujita Y, Hollnagel E. Failures without errors: quantification of context in HRA[J]. Reliability Engineering \& System Safety, 2004, 83(2): 145-151

18. Yao Wang, Xuhong He. Quantitative Analysis of Cognitive Errors 
